\title{
DESIGN AND IMPLEMENTATION OF ZETA MICRO-INVERTER FOR SOLAR PV APPLICATION
}

\section{S. VISHNU, S. VIGNESH \& A. SURENDAR}

Assistant Professor, School of Electronics, Vignan's University, Guntur, India

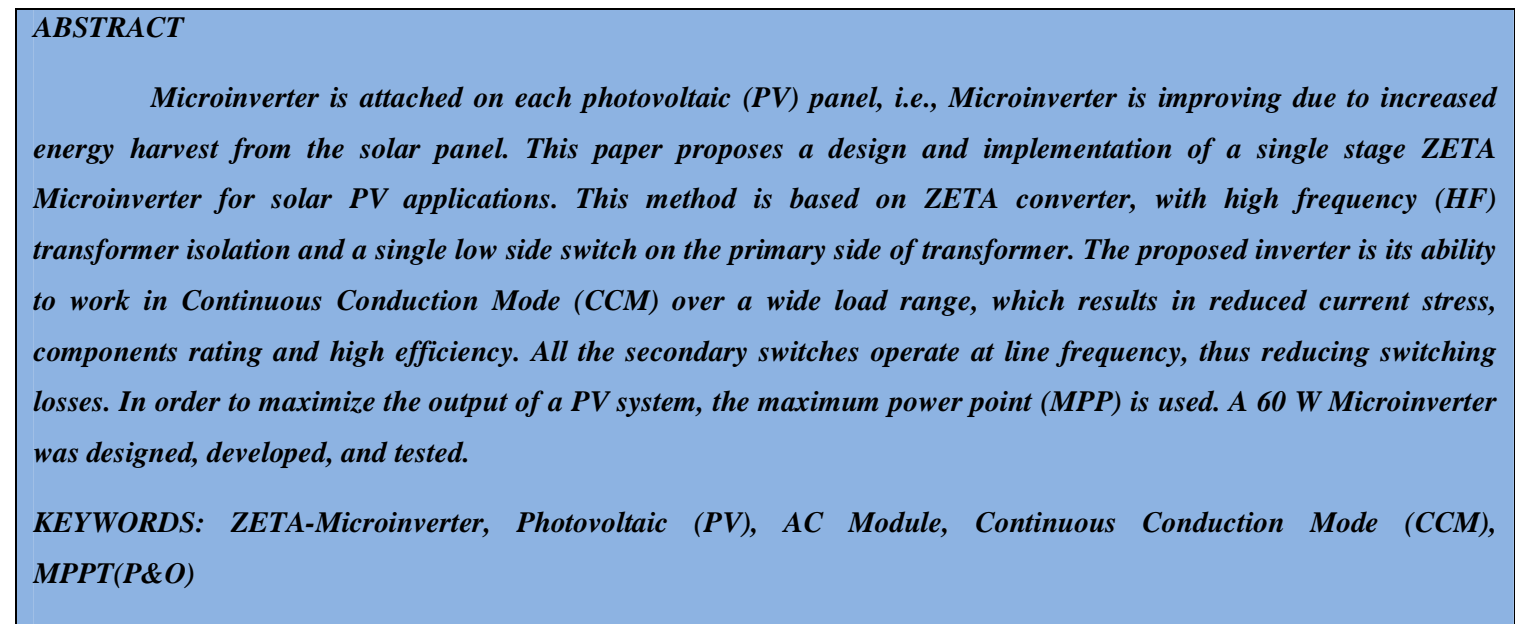

Received: Jun 24, 2017; Accepted: Jul 11, 2017; Published: Jul 21, 2017; Paper Id: IJMPERDAUG201722

\section{INTRODUCTION}

A series connected PV panels with a single large inverter (string inverter) can be used to feed power into the grid with a common Maximum Power Point Tracking (MPPT). However, this is an inefficient way of harvesting energy because individual MPPT of solar panels is not done. A panel mismatch, shading or formation of debris will reduce the energy harvest significantly. To solve the above-mentioned problem, the concept of Micro inverter is picking up. Micro inverters are attached at the back of a PV panel and directly generate ac with MPPT. Improving the efficiency, reducing number of power conversion stages, and scalability are major design considerations.

Basic DC-DC converters such as Buck, Boost and Buck-Boost were investigated to operate under basic feedback control where the controller gains are determined from the pole placement approach formulated in the Linear Matrix Inequalities (LMIs) framework. This control is able to improve DC-DC converters performance with regard to the step response and steady-state error. Controllers such as PID, also come as good choice, being applied in controlling inverters.

The single-stage Micro inverters, fly back converter with a line frequency inverter (LFI) is the most commonly reported topology as there is only one main switch on the primary. Most of the fly back inverters reported in literature operate under discontinuous conduction mode (DCM). DCM mode of operation leads to higher inverter losses, current stress and component rating compared to CCM operation. This is due to the control complexity caused by the right half plan (RHP) zero when fly back converter is operated in CCM. To address the 
problems in fly back inverter and to achieve CCM operation with a moving RHP zero, Li \& Oruganti proposed control strategies and demonstrated significant efficiency improvement.

Modelling of ZETA dc/dc converter and parameter selection to eliminate RHP zero was earlier reported. It is concluded that ZETA converter can achieve higher bandwidth, and good closed loop stability. A DCM mode ZETA converter based inverter was earlier reported. The inverter power rating was limited to 80W. Low switching frequency (20 $\mathrm{kHz}$ ) operation resulted into a larger filter and transformer.

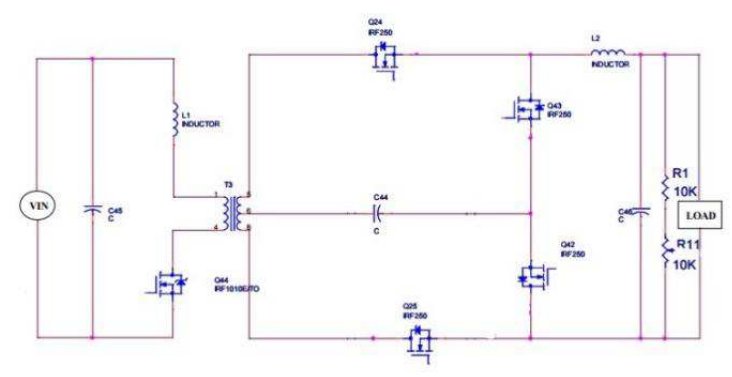

Figure 1: ZETA Microinverter

In this paper, a single stage CCM ZETA Micro inverter is proposed, with a single primary switch and four secondary switches.

\section{PROPOSED TOPOLOGY AND DETAILED ANALYSIS OF CCM ZETA MICROINVERTER}

This Section the steady-state operation of proposed Micro inverter. To simplify analysis, the following assumptions are made:

- All semiconductor devices are ideal and lossless

- Input voltage ripple is negligible.

Operation of ZETA Micro inverter is described for the +ve half cycle of load current at switching frequency. The main switch $S_{m}$ is fixed at High Frequency with a variable duty cycle to generate rectified AC output and Secondary Switches $S_{1}-S_{4}$ are operated. On the secondary side, during +ve half cycle of load current switches $S_{1}, S_{3}$ are gated to conduct and during -ve half cycle of load current, switches $S_{2}, S_{4}$ are conduct by giving gate signal.

\section{CCM Mode of Operation}

\section{Interval $1\left(t_{c 0}<t<t_{c 1}\right)$}

At $t=t_{\mathrm{c} 0}$, the main switch $S_{m}$ is tuned-on and secondary switches $S_{1}, S_{3}$ are conducting throughout the positive half cycle. This interval is common to both DCM and CCM but prior to this interval the voltage across the primary of the transformer is non-zero, thus the current in the primary starts from a minimum value. In this interval input voltage, $V_{i n}$ is applied across the magnetizing inductance $L_{m}$ of the transformer. Diode $D_{\mathrm{s} 2}$ is reverse biased, thus the secondary switch current $i_{\mathrm{s} 2}=0$ in this interval. Mathematical equations for the various current are

$$
\begin{aligned}
& ()=(0)+\left[-+\frac{2}{0}\right](-0) \\
& ()=\left(\begin{array}{l}
0 \\
0
\end{array}\right)+[-](-0)
\end{aligned}
$$




$$
()=\left[\frac{()-()}{C}\right]={ }_{0}()=()
$$

At the end of this interval, flying capacitor is discharged to $V_{c f_{-} m i n}$, currents $I_{p}, I_{L m}$ and $I_{L o}$ reach their peak values which can be represented by $I_{p \_p e a k}, I_{L m \_p e a k}$ and $I_{L o \_p e a k}$, respectively and are given by

$$
\begin{array}{ll}
\left(\begin{array}{ll}
1 \\
1
\end{array}\right)= & =\left({ }_{0}\right)+[-](\quad) \\
\left(\begin{array}{l}
1 \\
1
\end{array}\right)= & =\frac{-}{}
\end{array}
$$

This interval with duration $D T_{\mathrm{s}}$ ends when the main switch $S_{m}$ is tuned-off.

\section{Interval $2\left(t_{c 1}<t<t_{c 2}\right)$}

At $t=t_{\mathrm{c} 1}$ the main switch $S_{m}$ is turned-off and secondary side diode $D_{\mathrm{s} 2}$ goes into conduction. At the start of this interval, the diode current is equal to peak primary current $I_{p \_ \text {peak }}$ referred to secondary. Flying capacitor voltage $V_{C f}$ appears across the magnetizing inductance, but the average voltage across the output capacitor and the flying capacitor is equal for given switching cycle $\left(\left\langle V_{c f}\right\rangle=\left\langle V_{o}\right\rangle\right)$. Hence, for higher values of flying capacitance, $v_{c f}$ is approximately equal to the output voltage $V_{0}$ thus the current in flying capacitor $I_{c f}$ increases linearly with a slope $\operatorname{Vo} /\left(n^{2} L_{m}\right)$ thus, expression for switch current. For CCM operation, switch $S_{m}$ is turned-on before the diode current reaches zero. Thus, the currents at the end of this interval are equal to currents at the start of next interval. From the above analysis, it should be realized that CCM operation of ZETA Micro inverter results into lower RMS to average current ratio compared to DCM mode as the current ripple in the inductors $L_{M}, L_{o}$ are reduced. This will in turn translate into improved inverter efficiency as the conduction losses are reduced.

\section{DESIGN EXAMPLE FOR CCM ZETA MICROINVERTER}

This Section presents the major design guidelines for ZETA Micro inverter operating in CCM. The specifications are:

- Input voltage $V_{\text {in }}=30-40 \mathrm{~V} \mathrm{DC}$,

- $\mathrm{V}_{\mathrm{o}}=230 \mathrm{~V}, 50 \mathrm{~Hz} \mathrm{AC}$

- $\quad$ Rated power $=60 \mathrm{~W}$.

\section{Average Input Current}

The average input current of the inverter can be derived from the efficiency $(\eta)$ of the inverter as

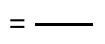

\section{Switch Selection}

The primary switch selection $S_{m}$ is important because it operates at High Frequency and carries the highest current in the circuit. Maximum voltage that appears across devices is

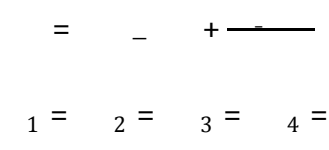


Where, $V_{\text {in_max }}$ and $V_{\text {o_peak }}$ are the maximum input voltage of PV panel, which is $40 \mathrm{~V}$ respectively.

\section{Open Loop Modulator}

The proposed inverter is buck boost derived (i.e.,) the output of the flyback transformer is stepped down and boosted for the desired output. The gain varies non-linearly with duty cycle, so a non-sinusoidal modulating signal should be used which can be derived as

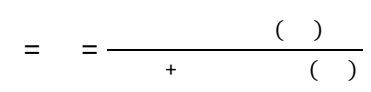

\section{Transformer Turns}

To select the transformer turns, it is required to know the DC gain of the inverter. In an ideal case when operating in CCM a voltage of $V_{\text {in }}$ appears across the transformer, when the switch is turned-on and the voltage of $V_{o}$ appears when the switch is tuned-off.

$$
(\quad)-(1-)=0
$$

Duty cycle of the inverter is varied such that the output voltage waveform is a rectified sine wave i.e.

$$
-=\frac{}{1-}
$$

Thus, the transformer turns ratio should be selected such that least possible input voltage should be translated up to peak output voltage using

$$
0=(\quad)
$$

For this design $V_{\text {in_min }}, D_{\max }$ are taken as $30 \mathrm{~V}$ and 0.65 respectively.

$$
=\frac{(1-\quad)}{-}
$$

The transformer required for ZETA Micro inverter is the same as that of conventional fly back transformer, which stores energy when the main switch $S_{\mathrm{m}}$ is turned-on and releases energy, when $S_{\mathrm{m}}$ is turned-off. By using an air-gap core, the energy storage capacity of the transformer is increased. In case of Micro inverter, sufficient air-gap has to be given to allow the energy storage without saturation at peak input voltage and for peak power transfer.

\section{Input Capacitor}

While the power output of the Micro inverter is time varying, the input power from PV panel must be maintained constant at average value to increase the energy harvest. Thus a large capacitor needs to be connected across PV panel to balance this difference. Voltage ripple due to insufficient capacitance has a significant impact on the MPPT performance and to maintain MPPT efficiency at $99 \%$ the maximum voltage ripple allowed is limited to $5 \%$.

$$
=\overline{2}
$$

Where, $f=$ frequency.

At $V_{\text {in }}=40 \mathrm{~V}, 60 \mathrm{~W}$, allowing $5 \%$ input voltage ripple requires input capacitor of $15 \mathrm{mF}$. This is a large electrolytic capacitor, and usually expected to have short lifespan. 


\section{$L_{m}$ and Switching Frequency fs}

The values of $L_{m}$ and $f_{s}$ are selected such that, the inverter operates in CCM throughout the power range. Generally, at higher switching frequency the value of magnetizing inductance required to keep the inverter in CCM will reduce. It will increase the switching losses and transformer core losses. The relationship between $L_{m}, f_{s}$ is given as

$$
=(=1)-
$$

Selecting $\Delta I_{L M}<I_{i n}$, proposed Microinverter can be operated in CCM. At full load with $92 \%$ efficiency, $I_{i n}$ is calculated as $1.5 \mathrm{~A}$. To ensure CCM at rated power with $L_{m}=3.72 \mathrm{mH}$, switching frequency $f_{s}$ should be greater than $8 \mathrm{kHz}$. In this design example, switching frequency is taken as $10 \mathrm{kHz}$.

\section{Flying Capacitor $\mathbf{C}_{\mathbf{f}}$}

Flying capacitor $C_{f}$ is computed to limit the voltage ripple $\left(\Delta V_{c f}\right)$ in the capacitor to a minimum value, taking $\Delta V_{c f}$ $=5 \% \times V_{\text {o_peak }}$, and the value of capacitance is computed as

\section{AC Filter Design}

The output inductor $L_{o}$ value can be determined based on maximum allowable current ripple in the inverter using

$$
0=-
$$

Where $\Delta I=I_{L o \_p e a k} I_{L o}\left(t_{\mathrm{c} 0}\right)$. The filter capacitor $C_{o}$ can be obtained from the ac filter cut off frequency $f_{\mathrm{c}}$ that is usually taken as one tenth of the switching frequency $f_{\mathrm{s}}\left(f_{\mathrm{c}}=10 \% \mathrm{x} f_{\mathrm{s}}\right)$

\section{Active-Clamp}

When the main switch $S_{m}$ is turned-off, a voltage spike appears across it due to the energy stored in the leakage inductance of transformer. This will necessitate use of overrated switches and will reduce the inverter efficiency. Instead, an active-clamp with a small auxiliary switch $\left(S_{\text {ac }}\right)$ and a series capacitor as shown in Figure 2 can be added. The activeclamp eliminates turn-off spike and recycle the parasitic energy back to the inverter.

$$
=\frac{1}{2 \sqrt{ }}
$$

This improves the inverter efficiency by limiting the device voltage.

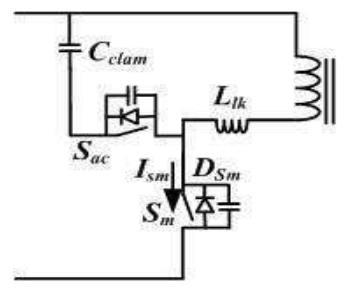

Figure 2: Active Clamp for Main Switch $S_{m}$.

\section{SIMULATION RESULT}

In Figure 3a, Figure 3b shows the input and output, current and voltage of ZETA inverter. From the results, it is 
clear that ZETA inverter provides a proper tracking for the PV panels with reduced oscillations.

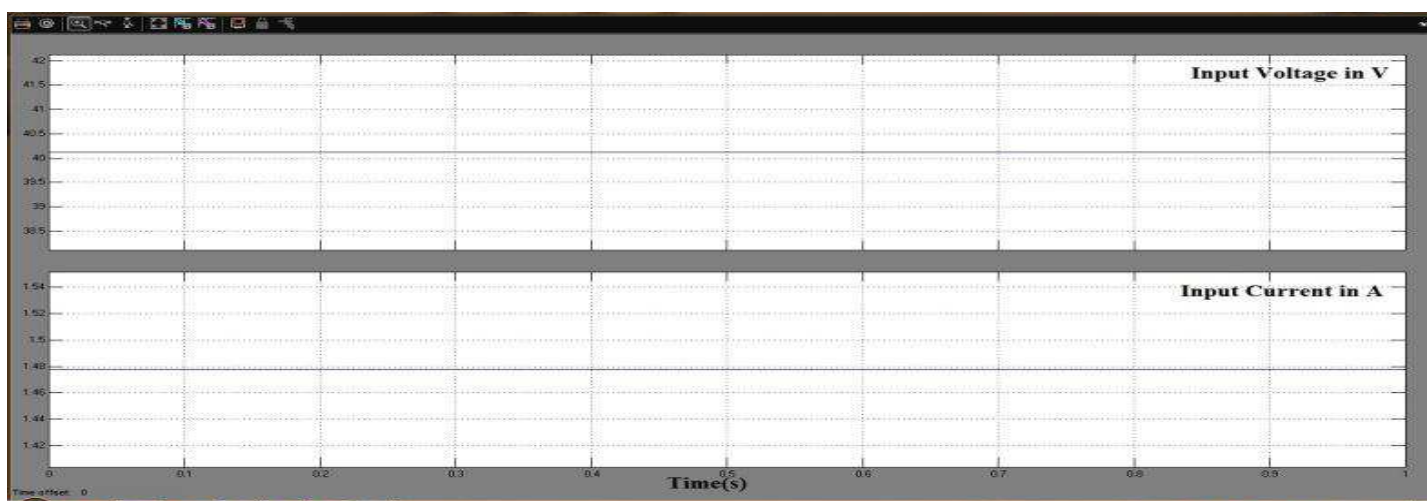

Figure 3.a: Input Response of ZETA Inverter

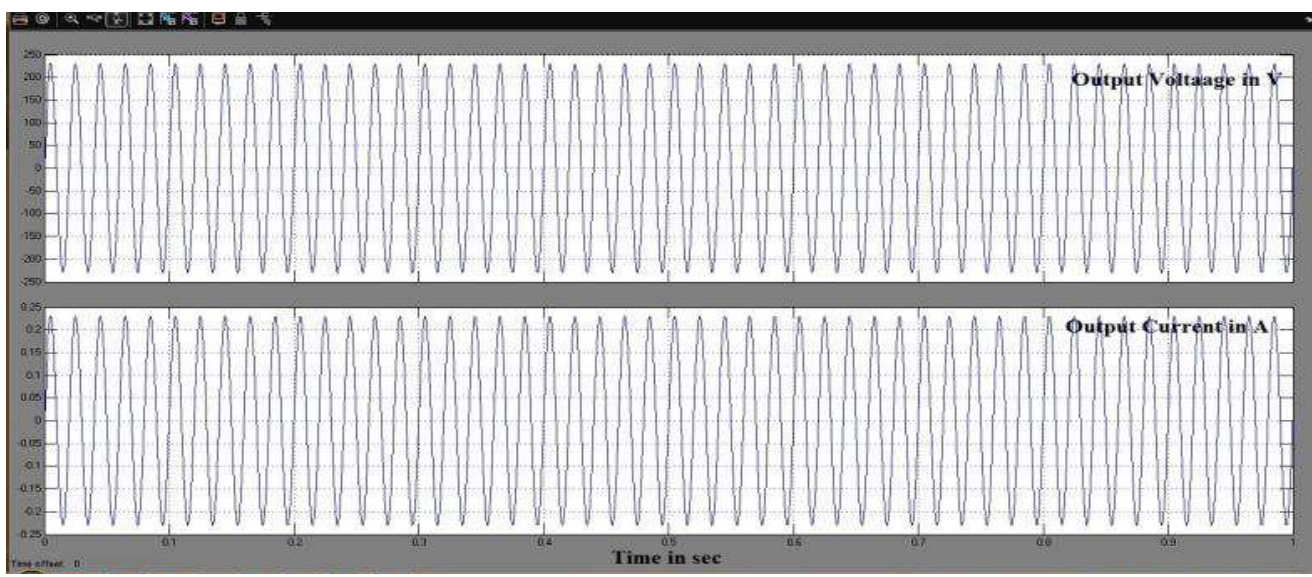

Figure 3.b: Output Response of ZETA Inverter

\section{CONCLUSIONS}

Design and implementation of ZETA Micro inverter has been proposed for solar Photo Voltaic AC module. Steady-state operation and analysis of proposed ZETA Micro inverter in CCM has been studied. Micro inverter operation in CCM mode results in

- $\quad$ Reduced conduction losses,

- $\quad$ Switch ratings and

- $\quad$ Current stress.

Traditional Continuous Conduction Mode, fly back inverters have closed loop complexity and stability issues. The proposed inverter provides High Frequency isolation and has only a single switch operating at High Frequency, which will reduce the switching losses. The circuit is simple and easy to develop. A $60 \mathrm{~W}$ inverter has been developed and simulation tests are done. The simulation results have a peak efficiency of $95 \%$ at rated power of $60 \mathrm{~W}$.

\section{REFERENCES}

1. Q. Li and P. Wolfs, "A review of the single phase photovoltaic module integrated converter topologies with three different DC link configurations," IEEE Trans. Power Electron., vol. 23, no. 3, pp. 13201333, May.2008. 
2. C. Rodriguez and G. Amaratunga, "Long-lifetime power inverter for photovoltaic AC modules," IEEE Trans. Ind. Electron., vol. 55, no. 7, pp. 2593-2601, Jul.2008.

3. B. Liu, S. Duan and T. Cai, "Photovoltaic DC-building-module-based

4. BIPV system--Concept and design considerations," IEEE Trans. Power Electron., vol. 26, no. 5, pp. 1418-1429, Jun.2011.

5. S. Jiang, D. Cao, Y. Li, and F. Z. Peng, "Grid-Connected Boost-HalfBridge Photovoltaic Microinverter System Using Repetitive Current

6. Control and Maximum Power Point Tracking," IEEE Trans. Power Electron., vol. 27, no. 11, pp. 4711-4722, Nov. 2012.

7. W.-Y. Choi, "High-Efficiency DC-DC Converter With Fast Dynamic Response for Low-Voltage Photovoltaic Sources,” IEEE Trans. Power Electron., vol. 28, no. 2, pp. 706-716, Feb. 2013.

8. Nayanasiri, D. R., D. M. Vilathgamuwa, and D. L. Maskell., "HalfWaveCycloconverter Based Photovoltaic Microinverter Topology with Phase Shift Power Modulation,” IEEE Trans. Power Electron, vol. 28, no. 6, pp. 2700-2710, Jun.2013.

9. H. Patel and V. Agarwal, “A single-stage single-phase transformer-less doubly grounded grid-connected PV interface,” IEEE Trans. Energy Convers., vol. 24, no. 1, pp. 93-101, Feb.2009.

10. W. Yu, J.-S. Lai, H. Qian, C. Hutchens, J. Zhang, "High-efficiency inverter with H6-type configuration for photovoltaic nonIsolated AC module applications," inProc. of IEEE Applied Power Electronics Conference and Exposition(APEC), Palm Springs, CA, pp. 1056-1061, Feb. 2010.

11. B. Yang, W. Li, Y. Gu, W. Cui and X. He, "Improved transformerless inverter with common-mode leakage current elimination for a photovoltaic grid-connected power system," IEEE Trans. Power Electron., vol. 27, no. 2, pp. 752-762, Feb.2012.

12. Yu-Kang Lo and Jing-Yuan Lin, “Active-clamping ZVS flyback converter employing two transformers,” IEEE Trans. Power Electron., vol. 22, pp. 2416-2423, Nov.2007.

13. T. Shiizu, K. Wda, and N. Nakmura, "Flyback-tpe sigle-phase utility interactive inerter with power pulsation dcoupling on the dc input for an ac photovoltaic moule sysem," IEEE Trans. Power Eletron., vol. 22, no. 5, pp. 1264-122, Sep. 2006.

14. F. Shinjo, K. Wada and T. Shimizu, "A single-phase grid-connected inverter with a power decoupling function," in Proc. IEEE Power Electron. Spec. Conf.(PESC), pp. 1245-1249, Jun.2007.

15. H. Haibing, S. Harb, F. Xiang, Z. Dehua, Z. Qian, Z. J. Shen and I. Batarseh, "A three-port flyback for PV Microinverter applications with power pulsation decoupling capability," IEEE Trans. Power Electron., vol. 27, no. 9, pp. 3953-3964, Sept.2012.

16. H. Haibing, S. Harb, N.H. Kutkut, Z.J. Shen and I. Batarseh, "A single stage Microinverter without using electrolytic capacitors,” IEEE Trans. Power Electron., vol. 28, no. 5, pp. 2677-2687, Jun.2013.

17. C. Kyritsis, E. C. Tatakis and N. P. Papanikolaou, "Optimum design of the current-source flyback inverter for decentralized grid-connected photovoltaic systems," IEEE Trans. Energy Convers., vol. 23, no. 1, pp. 281-293, Mar.2008.

18. L. Yanlin and R. Oruganti, “A low cost flyback CCM inverter for ac module applications,” IEEE Trans. Power Electron., vol. 27, no. 3, pp. 1295-1303, Mar.2012.

19. F. Fongang Edwin, W. Xiao and V. Khadkikar, "Dynamic modeling and control of interleaved flyback module-integrated converter for PV power applications,” IEEE Trans. Ind. Electron., vol. 61, no. 3, pp. 1377-1388, Mar.2014.

20. Vuthchhay, E; Bunlaksananusorn, C; “Modeling and Control of a ZETA Converter," in proc. Power electronics conference (IPEC), pp. 612-619, Jun. 2010. 
21. Viero, R.C.; Lopez, H.F.M.; Zollmann, C.A.; dos Reis, F.S., "Dynamic modeling of a sinusoidal inverter based on ZETA converter working in DCM for PV arrays," in proc. 36th Annual Conference on IEEE Industrial Electronics Society(IECON), pp. 439-444, Nov.2010.

22. J. S. Shaffer. (2009). Evaluation of Electrolytic Capacitor Application in EnphaseMicroinverters. [Online]. Available: http://enphase.com/

23. Kyocera Solar “ 60 cell PV module,” KD 200-60 F series datasheet, Available: $\underline{\text { htp: }: / w w w . k y o c e r a s o l a r . c o m / a s s e t s / 001 / 5130 . p d f}$

24. J. C. Salmon, "Techniques for minimizing the input current distortion of current-controlled single-phase boost rectifiers," IEEE Trans. Power Electron, vol. 8, no. 4, pp. 509-520, Oct.1993. 